\title{
Average annual cost of Parkinson's disease in São Paulo, Brazil, with a focus on disease-related motor symptoms
}

This article was published in the following Dove Press journal: Clinical Interventions in Aging

\author{
Tânia M Bovolenta' \\ Sônia Maria Cesar de \\ Azevedo Silva ${ }^{2}$ \\ Roberta Arb Saba ${ }^{3}$ \\ Vanderci Borges ${ }^{2}$ \\ Henrique Ballalai Ferraz ${ }^{2}$ \\ Andre C Felicio' \\ 'Hospital Israelita Albert Einstein, \\ São Paulo, ${ }^{2}$ Neurology Department, \\ Federal University of São Paulo, \\ UNIFESP, São Paulo, ${ }^{3}$ Neurology \\ Department, Federal University of São \\ Paulo, UNIFESP, São Paulo, Brazil
}

Correspondence: Andre C Felicio Hospital Israelita Albert Einstein, Avenida Albert Einstein, 627/70I - Morumbi CEP, 0565I-90I São Paulo (SP), Brazil Tel +55 II 215। 9205

Email cf.andre@gmail.com
Background: Although Parkinson's disease is the second most prevalent neurodegenerative disease worldwide, its cost in Brazil - South America's largest country - is unknown.

Objective: The goal of this study was to calculate the average annual cost of Parkinson's disease in the city of São Paulo (Brazil), with a focus on disease-related motor symptoms.

Subjects and methods: This was a retrospective, cross-sectional analysis using a bottom-up approach (ie, from the society's perspective). Patients $(\mathrm{N}=260)$ at two tertiary public health centers, who were residents of the São Paulo metropolitan area, completed standardized questionnaires regarding their disease-related expenses. We used simple and multiple generalized linear models to assess the correlations between total cost and patient-related, as well as diseaserelated variables.

Results: The total average annual cost of Parkinson's disease was estimated at US\$5,853.50 per person, including US\$3,172.00 in direct costs (medical and nonmedical) and US\$2,681.50 in indirect costs. Costs were directly correlated with disease severity (including the degree of motor symptoms), patients' age, and time since disease onset.

Conclusion: In this study, we determined the cost of Parkinson's disease in Brazil and observed that disease-related motor symptoms are a significant component of the costs incurred on the public health system, patients, and society in general.

Keywords: Parkinson's disease, health economics, cost of illness, health evaluation, cost analysis

\section{Introduction}

By 2030, the number of individuals with Parkinson's disease (PD) will be approximately 9 million worldwide. ${ }^{1}$ In a survey conducted in 28 European countries, PD was classified as the fourth most expensive disease among the 12 most prevalent and costly neurologic disorders. ${ }^{2}$ Although methodologies differ among epidemiologic studies, the prevalence of PD in industrialized countries is estimated at $\sim 0 \%-3 \%$ of the entire population, $1 \%$ of individuals over 65 years old, and $3 \%-5 \%$ of individuals 85 or older. ${ }^{3,4}$ The incidence of PD varies between eight and 18/100,000 persons/year, although one study conducted in Argentina reported a rate of 31.2/100,000 persons/year. ${ }^{3,5}$

Knowing the costs associated with a given disease is critical to formulate, prioritize, and allocate health resources as well as to develop therapies and/or interventions applied by public health managers, insurance companies, as well as patients and their families. Although several variables affect costs, most studies typically focus strictly on disease severity and duration. ${ }^{6-10}$ Studies about PD-associated costs have been 
conducted worldwide, ${ }^{6,11,12}$ but are relatively rare in South America, where notifying PD is not compulsory.

The annual cost of PD is positively correlated with disease severity, such that costs increase with PD progression and may even double with each score on the modified Hoehn and Yahr (H\&Y) scale. ${ }^{13,14}$ Furthermore, the combination of symptoms and the potential side effects of antiparkinsonian medications may adversely affect patients' quality of life and result in higher costs to the society. ${ }^{15-19}$

In this study, our goal was to estimate the mean annual cost of PD in São Paulo - Brazil's most economically developed city - and to assess the impact of motor symptoms specifically, by the societal perspective. We also assessed the indirect and direct (medical and nonmedical) costs and correlated them with several sociodemographic and clinical variables.

\section{Subjects and methods Participants and study design}

A total of 390 patients were contacted between October 2015 and September 2016 during outpatient visits at two tertiary centers in the city of São Paulo: the Hospital at the Universidade Federal de São Paulo (Institution 1) and the Hospital do Servidor Público Estadual (Institution 2). Three patients chose not to participate and the remaining 387 agreed to receive the research material. A total of 268 questionnaires were returned by mail, eight of which were excluded because they were incomplete or the respondents did not properly follow the instructions.

Thus, the final group consisted of 260 patients with PD according to UK Parkinson's Disease Society Brain Bank criteria $^{20}$ (see Table 1 for patient characteristics). Symptom severity (measured during the "on" phase) and time since disease onset were provided by the physician during the visit. Patients were excluded if their PD costs were covered by private health insurance or if they had undergone surgery for PD. We decided to exclude patients who had undergone deep brain stimulation because Institution 2 did not have this expertise and, in spite of the growing number of patients operated on in Institution 1, we understood this could be addressed separately. Besides, surgery for PD in Brazil is still incipient and does not represent the PD-associated costs.

The questionnaire (Supplementary material) contained five parts: 1) direct medical costs (outpatient and/or private visits and antiparkinsonian medications); 2) direct nonmedical costs (ambulatory and/or private complementary treatments); 3 ) indirect costs (benefits given to patients who retired exclusively due to the illness and lost wages of caregivers who stopped working to take care of the patient);
Table I Patient characteristics

\begin{tabular}{ll}
\hline Personal, demographic, and disease-related variables \\
Gender, $\mathbf{n}(\%)$ \\
Male & $144(55.4)$ \\
Age, years & \\
Mean (SD) & $67.6(10.6)$ \\
Median (first quartile-third quartile) & $68(60-76)$ \\
Minimum-maximum & $40-89$ \\
Education level, $\mathbf{n}$ (\%) & \\
Never attended school & $19(7.3)$ \\
Completed grade school & $120(46.2)$ \\
Completed middle school/high school & $77(29.6)$ \\
Completed college & $39(15.0)$ \\
Completed graduate school & $5(1.9)$ \\
Current employment, $\mathbf{n}(\%)$ & \\
Retired & $217(83.5)$ \\
Retired with informal employment & $4(1.5)$ \\
Retired and employed & $2(0.8)$ \\
Unemployed & $10(3.8)$ \\
Employed & $12(4.6)$ \\
No income & $13(5.0)$ \\
Informal employment & $2(0.8)$ \\
Degree of illness (modified Hoehn and Yahr), $\mathbf{n}(\%)$ & \\
I & $17(6.5)$ \\
I.5 & $23(8.8)$ \\
2 & $66(25.4)$ \\
2.5 & $38(14.6)$ \\
3 & $70(26.9)$ \\
4 & $30(11.5)$ \\
Disease duration, ${ }^{\text {a }}$ years (\%) & $16(6.2)$ \\
$<5$ years & \\
$5-I 0$ years & $50(19.2)$ \\
$>$ I0 years & $106(40.8)$ \\
\hline & $104(40.0)$ \\
\hline
\end{tabular}

Note: ${ }^{A}$ At the time of study inclusion.

4) out-of-pocket expenses (expenses paid by the patient, including medications and equipment and/or home alterations to facilitate locomotion); and 5) sociodemographic data (age, gender, level of education, and financial situation).

After a face-to-face interview with the patient, explaining the purpose of our research, ethics, and the importance of reliability on data collection, our study questionnaire was sent via mail and patients were instructed to answer this form with the help of a caregiver. Also, with the purpose of minimizing recall bias, information on $\mathrm{PD}$-associated costs was requested covering the previous 6 months and then extrapolated to a full year. Whenever there was data or incorrect/doubtful/ incongruent information was filled in, the interviewer got in touch with the respective subject or caregiver.

This was an observational, cross-sectional, retrospective study about disease prevalence that used a bottom-up approach (ie, from the society's perspective). It was approved by the local Research Ethics Committee (Comitê de Ética em Pesquisa do Hospital Israelita Albert Einstein) under 
protocol number 45632915.1.0000.0071 on July 6, 2015, and all participants provided informed consent.

\section{Cost calculation}

Costs were calculated for the 6-month period prior to the interview and extrapolated to 1 year. Values are described in Real (\$) and US Dollar (USD) using the Brazilian Central Bank real-dollar quotation assessed on February 24, 2017.

To calculate the direct medical and nonmedical costs, we obtained data from public and legal sources of the Brazilian public health system, known as the Sistema Único de Saúde (SUS; http://aplicacao.saude.gov.br/bps and http://sigtap. datasus.gov.br). For patients who purchased drugs through private pharmacies or drugstores, we estimated the average market price at the time the research was conducted, and in cases where private therapists were hired, consultation fees were obtained directly from the professionals. Direct medical costs included the cost of medications and consultations purchased privately and through the SUS, while direct nonmedical costs included private and SUS-provided therapies, caregiver services, home adaptations, and the purchase of equipment to facilitate locomotion. We then added all medical and nonmedical costs to obtain the total direct costs. Indirect medical costs included the amount of benefits received (when reported in the questionnaire) as well as the last salary of caregivers who stopped working to assist the patient (reflecting the caregiver's loss of productivity).

\section{Pilot study}

Our initial questionnaire was designed based on previous international studies ${ }^{9,11,21,22}$ and contained 31 questions regarding PD-associated costs as well as personal, demographic, and socioeconomic data. To test its validity and improve its content, we randomly selected 21 patients to fill it out as part of a pilot study during the month of August 2015. Thirteen patients returned the questionnaire and based on their answers, we developed a final 22-item questionnaire with improved clarity and data reliability.

\section{Statistical analyses}

Categorical variables are described as absolute frequencies and percentages, and numerical variables as summary measures, such as means and SD or medians and quartiles (first and third quartiles), as well as minimum and maximum values.

Cost distribution was plotted in histograms and boxplots using the Shapiro-Wilk normality test, which revealed great variability and an asymmetric distribution.
The total annual cost was estimated by calculating the mean and $95 \% \mathrm{CI}$ obtained by adjusting a generalized linear model with a gamma probability distribution and log link function.

Generalized linear models were adjusted for the annual total cost with gamma probability distribution and log link function, as well as the following explanatory variables: factors related to the patient, the disease, and the place of recruitment (Institution 1 or 2). The models were constructed for each explanatory variable using a simple approach and later a multiple approach, which also took into account all the first-order interaction effects and applied a step-by-step variable selection process that searched for the variable combination that best explains the total cost.

Model results are presented by the estimated total cost means and $95 \%$ CIs and by the means' ratios and 95\% CIs. Multiple comparisons between category variables and the estimated costs were corrected by the Bonferroni method. ${ }^{23}$

To calculate caregivers' loss of productivity, we updated the lagged wage values, and current values were estimated by means of a correction model that takes into account the national consumer price index (Índice Nacional de Preços ao Consumidor) and the unemployment rate (used to estimate the probability that an individual will become unemployed at some point between the last salary collected and the current year). Both the Índice Nacional de Preços ao Consumidor and unemployment rates were obtained from government sources. For stability, we generated model simulations and used the obtained means to estimate the updated salary for each caregiver.

All analyses were conducted using $\mathrm{SPSS}^{24}$ and $\mathrm{R},,^{25}$ and significance was set at $5 \%$.

\section{Results}

A total of $54.6 \%$ of PD patients were from Institution 1 and the remaining $45.4 \%$ were from Institution 2 . Males made up $55.4 \%$ of the sample, $46.2 \%$ of all patients had completed elementary school, 223 patients $(85.8 \%)$ were retired, and 45 of them (17.3\%) received some form of government benefits exclusively due to PD. Most patients had an H\&Y score of 2.0 or 3.0 , and nearly $81 \%$ of patients had had the disease for more than 5 years at the time of study inclusion (Table 1).

Detailed analyses of the annual average costs associated with $\mathrm{PD}$, including direct, indirect, and total costs, are presented in Table 2, while the correlations between H\&Y scale scores and treatments, caregivers, and benefits are listed in Table 3.

All patients used at least one drug to treat $\mathrm{PD}$, and these drugs were grouped according to therapeutic class: $96.2 \%$ 
Table 2 Annual costs associated with Parkinson's disease

\begin{tabular}{|c|c|c|c|c|}
\hline Costs & $\begin{array}{l}\text { Mean } \\
\text { (US\$) }\end{array}$ & $\begin{array}{l}95 \% \mathrm{Cl}^{\mathrm{a}} \\
\text { (US\$) }\end{array}$ & $\begin{array}{l}\text { Minimum } \\
\text { (US\$) }\end{array}$ & $\begin{array}{l}\text { Maximum } \\
\text { (US\$) }\end{array}$ \\
\hline \multicolumn{5}{|l|}{ Direct medical costs } \\
\hline Cost of SUS medications & 1,260 & $\mathrm{I}, 120-1,417$ & 0.00 & $4,588.3$ \\
\hline Private medication costs & 206.4 & $|50.2-283|$. & 0.00 & $2,620.7$ \\
\hline Cost of SUS ${ }^{b}$ medical visits & 11.2 & $10.6-11.9$ & 6.4 & 38.7 \\
\hline Cost of private medical visits & 33.9 & $23.1-49.8$ & 0.00 & 774.3 \\
\hline Total & $\mathrm{I}, 5 \mid \mathrm{I} .5$ & I,396.5-1,635.8 & 38.2 & $5,156.2$ \\
\hline \multicolumn{5}{|l|}{ Direct nonmedical costs } \\
\hline Cost of SUS therapies & 27.6 & 19.2-39.7 & 0.00 & 506.3 \\
\hline Private therapy costs & 556.8 & $374.0-830.1$ & 0.00 & $13,474.0$ \\
\hline Cost of private caregiver services & 855.0 & $559.0-1,307.8$ & 0.00 & $16,958.7$ \\
\hline Cost of private home adaptations ${ }^{c}$ & 146.5 & $100.4-213.8$ & 0.00 & $6,453.0$ \\
\hline Cost of private equipment to facilitate locomotion ${ }^{c}$ & 74.6 & $51.8-107.3$ & 0.00 & $1,935.9$ \\
\hline Total & $\mathrm{I}, 660.5$ & $\mathrm{I}, 186.8-2,323.3$ & 0.00 & $19,068.9$ \\
\hline Total direct costs & $3,172.0$ & $2,832.1-3,552.6$ & 93.5 & $21,516.0$ \\
\hline \multicolumn{5}{|l|}{ Indirect costs } \\
\hline Cost of government benefits exclusively for Parkinson's disease & $1,230.0$ & $801.3-1,887.7$ & 0.00 & $63,000.00$ \\
\hline Cost of caregiver loss of productivity ${ }^{d}$ & $\mathrm{I}, 45 \mathrm{I} .62$ & $937.57-2,247.51$ & 0.00 & $148,2 \mid 3.86$ \\
\hline Total & $2,681.5$ & $\mathrm{I}, 776 . \mathrm{I}-4,048.3$ & 0.00 & $196,213.86$ \\
\hline Total cost & $5,853.5$ & $5,119.2-6,694$ & 93.5 & $67,726.3$ \\
\hline Total cost, excluding caregiver loss of productivity & $4,401.9$ & $3,887.4-4,984.3$ & 93.5 & $31,407.7$ \\
\hline
\end{tabular}

Notes: ${ }^{a} 95 \% \mathrm{Cl}$ for average costs estimated by generalized linear models; costs of 0 were substituted by 0.01 for model adjustment. bistema Único de Saúde (public health system). ${ }^{~ C}$ Costs not reported by patients were considered to be $0 .{ }^{d}$ Costs based on the salary of unpaid caregivers who stopped working to assist the patient.

Abbreviation: SUS, Sistema Único de Saúde.

used levodopa, $56.9 \%$ used dopamine agonists such as pramipexole, $22.3 \%$ used antiglutamatergics such as amantadine, 5.4\% used anticholinergics such as biperiden, and 1.5\% used monoamine oxidase inhibitors such as selegiline.

Another $36.2 \%$ of patients took other medications, including antidepressants and/or anxiolytics (30.0\%), antipsychotics (8.8\%), and medications for cognitive impairment (4.2\%). During the period of the study, $54.2 \%$ of patients had to privately pay for part or all of their medications, as some drugs were not available through the public system.

A total of $37.3 \%$ and $44.2 \%$ of patients, respectively, went to one or two outpatient visits exclusively for PD, and $10.4 \%$ paid for private consultations.
Regarding complementary treatments, $48.1 \%$ of patients had received at least one type of free therapy during the previous 6 months, including: physiotherapy (34.6\%), speech therapy (12.3\%), and nutritionist services (3.1\%). Another $24.6 \%$ paid for at least one other type of therapy.

The monthly amount of government benefits (indirect costs) due to PD ranged from R $\$ 800$ (US\$258) to R $\$ 5,250$ (US $\$ 1,694$ ), with half of the patients receiving up to $\mathrm{R} \$ 1,500$ (US\$484) and the interquartile range being R $\$ 880$ (US\$284)$\mathrm{R} \$ 2,200$ (US\$710). The time since retirement was between 6 months and 33 years. Considering the interval between the age of retirement due to illness and the legal age of retirement in Brazil (60 for women and 65 for men in 2017), benefits

Table 3 Correlation between costs and clinical and demographic characteristics according to disease severity

\begin{tabular}{|c|c|c|c|c|c|c|c|}
\hline & \multicolumn{7}{|c|}{ Modified Hoehn and Yahr disease severity scale } \\
\hline & I & 1.5 & 2 & 2.5 & 3 & 4 & 5 \\
\hline Number of patients & 17 & 23 & 66 & 38 & 70 & 30 & 16 \\
\hline Age (years) ${ }^{a}$ & $67.5(15.1)$ & $68.9(8.4)$ & $63.6(10.9)$ & $66.7(9.0)$ & $67.8(10.1)$ & $71.7(8.2)$ & $75.6(10.5)$ \\
\hline Disease duration (years) ${ }^{b}$ & $4(3 ; 6)$ & $6(4 ; 9)$ & $7(4 ; 11)$ & $9(7 ; 12)$ & $12(9 ; 15)$ & $13(10 ; 16)$ & $17(12 ; 25)$ \\
\hline Levodopa use (\%) & 94.1 & 95.7 & 95.5 & 100.0 & 95.7 & 96.7 & 93.8 \\
\hline Underwent therapies (\%) & 29.4 & 39.1 & 36.4 & 57.9 & 57.1 & 53.3 & 56.3 \\
\hline Has caregiver(s), n (\%) & $7(41.2)$ & II (47.8) & $34(5 \mathrm{I} .5)$ & $29(76.3)$ & $46(65.7)$ & $27(90.0)$ & $14(87.5)$ \\
\hline Has paid caregiver(s), n (\%) & I (5.9) & I (4.3) & $6(9.1)$ & $7(18.4)$ & $7(10.0)$ & II (36.7) & $10(62.5)$ \\
\hline Receives temporary or permanent benefits, $n$ (\%) & I (5.9) & $0(0.0)$ & $15(22.7)$ & $8(2 I . I)$ & $15(2 \mid .4)$ & $3(10.0)$ & $3(18.8)$ \\
\hline Cost by severity scale (US\$)c & 1,988 & 1,609 & 4,088 & 4,555 & 4,317 & 5,780 & 9,698 \\
\hline
\end{tabular}

Notes: a Age in means (SD). 'Disease duration in medians (quartiles). cMean estimated values for the total annual cost of Parkinson's disease. 
were anticipated by 0-32 years. Assuming patients accurately reported the monthly amount received, the government's indirect cost for patients who receive their retirement before the legal age ranged from 0 to $\mathrm{R} \$ 816,000$ (US\$263,300).

Of the $168(64.6 \%)$ patients who reported having at least one caregiver, 137 (81.5\%) were assisted by an unpaid relative. Of the $43(16.5 \%)$ patients with caregiver costs, four $(9.3 \%)$ had more than one paid caregiver.

Privately paid home adaptations and the purchase of equipment to improve locomotion were reported by $30.0 \%$ and $35.4 \%$ of patients, respectively.

\section{Inferential analyses}

Table 4 shows the inferential analyses of the total annual cost of PD and sociodemographic and clinical variables. The patients with the highest costs were those 63 years of age or younger. Also, average costs of patients with $>10$ years of illness were 2.1 times the average cost of patients with disease duration of $<5$ years $(p<0.001)$. Patients with bilateral and more severe disease (modified H\&Y scores between 2 and 5) had estimated average costs of at least twice the mean cost of patients with a score of 1 (ie, a strictly unilateral disease; $p<0.05$ for all scores compared to a score of 1 ).

Average costs of patients who underwent therapy were 1.65 times that of those who did not undergo nonpharmacologic therapy $(p<0.001)$, such as physical therapy, speech therapy, or nutritionist.

Patients who used antidepressants/anxiolytics in addition to PD medications were estimated to cost 1.5 times more than the mean cost of patients who used PD medications alone ( $p=0.004)$. Similarly, the mean cost of patients who used antipsychotics and/or medications for cognitive impairment in addition to PD medications was estimated at approximately twice the mean cost of patients who used PD medications alone $(p=0.001)$.

Next, we conducted inferential analyses excluding the amount paid for therapies to assess their impact on the total cost of the disease. Compared to patients who underwent

Table 4 Inferential analyses of the total annual cost of Parkinson's disease and sociodemographic and clinical variables (generalized linear models using the simple approach)

\begin{tabular}{|c|c|c|c|}
\hline Variables & $\begin{array}{l}\text { Estimated means } \\
(\text { US } \$)(95 \% \mathrm{CI})^{\mathrm{a}}\end{array}$ & MR $(95 \% \mathrm{Cl})^{b}$ & $p$-value \\
\hline \multicolumn{4}{|l|}{ Age, years } \\
\hline$\leq 63$ & $5,47 \mid(4,453-6,722)$ & 1.00 & \\
\hline $64-73$ & $3,389(2,754-4,173)$ & $0.62(0.46-0.83)$ & 0.001 \\
\hline$\geq 74$ & $4,306(3,445-5,388)$ & $0.79(0.58-1.07)$ & 0.123 \\
\hline \multicolumn{4}{|l|}{ Gender } \\
\hline Female & $4,374(3,631-5,268)$ & 1.00 & \\
\hline Male & $4,424(3,744-5,228)$ & $1.01(0.79-1.30)$ & 0.928 \\
\hline \multicolumn{4}{|l|}{ Disease duration, years } \\
\hline$<5$ & $2,727(2,07 \mid-3,589)$ & 1.00 & \\
\hline $5-10$ & $3,813(3,157-4,605)$ & $1.40(1.00-1.95)$ & 0.049 \\
\hline$>10$ & $5,807(4,800-7,027)$ & $2.13(1.52-2.98)$ & $<0.001$ \\
\hline \multicolumn{4}{|l|}{ Disease severity (modified Hoehn and Yahr) } \\
\hline I & $1,988(1,260-3,137)$ & 1.00 & \\
\hline 1.5 & $\mathrm{I}, 609(\mathrm{I}, 087-2,382)$ & $0.81(0.44-1.48)$ & 0.491 \\
\hline 2 & $4,088(3,243-5,153)$ & $2.06(1.23-3.43)$ & 0.006 \\
\hline 2.5 & $4,555(3,357-6,181)$ & $2.29(1.32-3.97)$ & 0.003 \\
\hline 3 & $4,317(3,448-5,405)$ & $2.17(1.31-3.61)$ & 0.003 \\
\hline 4 & $5,780(4,100-8,148)$ & $2.91(1.64-5.15)$ & $<0.001$ \\
\hline 5 & $9,698(6,060-15,520)$ & $4.88(2.53-9.39)$ & $<0.001$ \\
\hline \multicolumn{4}{|l|}{ Medication use } \\
\hline For Parkinson's disease only & $3,540(3,042-4,119)$ & 1.00 & \\
\hline \multicolumn{3}{|l|}{ disease medications } & 0.004 \\
\hline Antipsychotics and/or medications for cognitive & $6,690(4,902-9,884)$ & $1.97(1.34-2.88)$ & 0.001 \\
\hline \multicolumn{4}{|l|}{ impairment + Parkinson's disease medications } \\
\hline \multicolumn{4}{|l|}{ Use of therapies } \\
\hline No & $3,357(2,836-3,973)$ & 1.00 & \\
\hline Yes & $5,530(4,642-6,589)$ & $1.65(1.29-2.10)$ & $<0.001$ \\
\hline
\end{tabular}

Notes: a Mean estimated values for the total annual cost of Parkinson's disease (US\$) and $95 \% \mathrm{Cls}$. bMR, means ratio; $95 \% \mathrm{Cl}$ for the estimated means ratio. Abbreviation: MR, means ratio. 
A

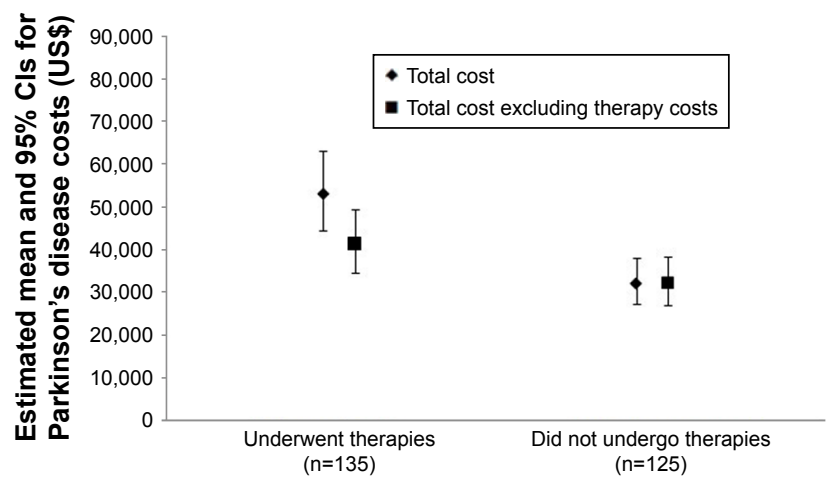

B

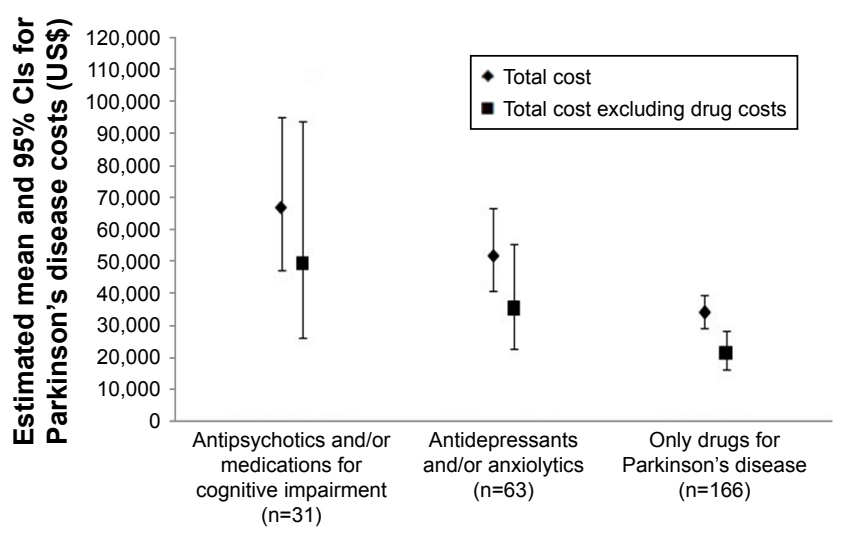

Figure I Estimated means and 95\% Cls for the total annual cost of Parkinson's disease considering complementary therapies (A) and drug use (B), when comparison was made between groups of patients.

no complementary therapies, those who had undergone at least one session of complementary therapy (physical therapy, speech therapy, occupational therapy, psychologist, nutritionist, physical educator, acupuncture, or others) presented a higher total mean cost (difference of $\mathrm{R} \$ 6,736.36$ [US\$2,173]; 95\% CI: R \$3,260.98 [US\$1,052]-R \$10,211.75 [US\$3,295]; $p<0.001$ ). Groups did not otherwise differ from each other when these costs were excluded from the analyses (Figure 1A).

Next, patients were divided according to drug treatment and compared in terms of total PD costs. Patients who used drugs other than those for PD had higher total costs than those who used only PD medications (a difference of $\mathrm{R} \$ 10,601.48$ [US\$3,420], 95\% CI: R $\$ 2,856.51$ [US\$922]-R $\$ 18,346.45$ [US $\$ 5,920$ ]; $p=0.022$ compared to the group of patients who used antipsychotics and/or medications for cognitive impairment, and a difference of R $\$ 5,809.26$ [US $\$ 1,874$ ], 95\% CI: $\mathrm{R} \$ 1,359.55$ [US $\$ 439$ ]-R $\$ 10,258.98$ [US $\$ 3,310] ; p=0.032$ compared to patients who used antidepressants/anxiolytics). There was no difference in costs between patients who used antipsychotics and/or medications for cognitive impairment and those who used antidepressants/anxiolytics $(p=0.827)$. Excluding these medication-related costs eliminated differences between groups (Figure 1B).

\section{Discussion}

This is the first study on the cost of PD conducted in Brazil, South America's largest country. Our data revealed an average annual cost of PD per patient of $\mathrm{R} \$ 18,141.64$ (US\$5,853.50), including $53.4 \%$ direct costs and $46.6 \%$ indirect costs. We also found that costs are significantly correlated with patient age as well as disease duration and severity. Compared with the use of other drugs and therapies, motor symptoms had a significantly greater impact on PDassociated costs.

Since there is no standardized, validated instrument to study the costs of PD, previous studies vary greatly in methodology as well as results, ${ }^{6,26}$ with authors independently deciding how to classify the variables studied.

Medications are usually the first aspect studied when researching the costs of a disease. In our study, antiparkinsonian drugs were responsible for $25.0 \%$ of the total cost (both drugs provided by the public health system and those purchased privately by patients) and $97.0 \%$ of direct medical costs. In one review study, ${ }^{19}$ drug therapy accounted for $15 \%-80 \%$ of total direct costs. Prescription is undoubtedly an important component of costs: as compared to our study, one study conducted in Brazil ${ }^{27}$ and another in Italy ${ }^{28}$ showed that the use of levodopa varied between $96.9 \%, 87.5 \%$, and $92.9 \%$, respectively, as did the use of pramipexole $(56.9 \%$, $20.8 \%$, and $77.1 \%)$ and amantadine $(22.3 \%, 23.6 \%$, and $8.6 \%$ ), certainly leading to significant variations in final medication costs. While countries such as Germany and Norway differ significantly in how they prescribe medications at different stages of the disease, in both countries, PD drugs accounted for $44 \%$ of the total disease cost. ${ }^{29}$

We observed in our sample that levodopa was prescribed at all stages of the disease, including the early stages (Table 3), indicating a reduced belief in the notion that the drug may induce early motor complications in patients, at least in tertiary services. Of the 92 patients 63 years of age or younger (Table 4), 56 (61\%) also used a dopamine agonist (pramipexole), which certainly raised the costs, considering that dopamine agonists in Brazil are significantly more expensive than levodopa. On the other hand, optimizing treatment by combining levodopa with dopamine agonists 
may explain why indirect costs were lower than direct costs, since the patient remains independent for a longer period, still working, thus decreasing the costs on the state.

Regarding direct nonmedical costs, $51.9 \%$ of our patients did not use any type of complementary therapy, either because free services were unavailable or difficult to access or their physician did not recommend them. In Brazil, several such services are offered to patients at zero or reduced costs by some cities, programs developed for the elderly, associations exclusively dedicated to aid PD patients, or even universities, but these services often fail to reach their target audience. A recent review study ${ }^{30}$ on the impact of physical activity in PD showed the role of these therapies in inducing plasticity in several brain regions, especially if performed for at least 45-60 minutes 2-3 times/week. In our sample, $26.9 \%$ of patients who practiced some type of therapy did so with this type of frequency and almost $60 \%$ of all who underwent some type of treatment had scores between 2.5 and 3.0 on the H\&Y scale.

Regular exercise and physical therapy work as a complement to the medical treatment of PD. Increasing evidence suggests that these types of therapies should be encouraged as they can improve motor performance and potentially delay the progression of symptoms; they are especially recommended early on in the disease to maintain physical fitness levels. ${ }^{31}$ We note that $82.2 \%$ of our patients had H\&Y scores between 1 and 3 (ie, mild to moderate disability), which makes them ideal candidates for physical activity. Furthermore, we observed that therapies did not significantly add to the total cost of the disease (Figure 1A), which is one more reason to recommend them.

As it is a late-onset, long-term illness (Table 3), PD usually manifests when the patient is already close to retirement due to length of service or age. In our sample, 17.3\% of patients were retired because of the disease and were still at a productive age (mean $=57.3$ years; retirement in Brazil usually occurs at 60 and 65 years of age for women and men, respectively). The benefits provided to these patients by the government accounted for $21 \%$ of the total cost and $45.8 \%$ of the indirect cost, just below that presented in a review study conducted in Germany ${ }^{19}(30 \%-60 \%$ of the total cost). The mean duration of the disease was 10.3 years at the time of study inclusion, meaning that patients had been receiving retirement benefits (a significant cost to the state) for quite some time. A study conducted in the $\mathrm{UK}^{32}$ revealed that most PD patients continued to work full-time or part-time for up to 10 years before losing their jobs. In Finland, ${ }^{21}$ the average retirement age of patients with PD is 52.8 years, well below the 58-59 years of the general population in the 1990s. In our study, $7.7 \%$ of patients did some type of work (either through regular or informal employment) and none of the 45 patients who retired due to the disease declared having any other form of gainful activity.

As many as $64.6 \%$ of our patients had at least one caregiver, and $16.5 \%$ of them paid them privately (Table 3 ). Considering that 223 of our patients were retired (by law or illness) and that the average amount of annual benefits received was $\mathrm{R} \$ 3,811.00$ (US\$1,230), the amount paid to caregivers (R\$2,649.00; US\$855) is relatively high. As in Brazil, in Singapore, ${ }^{11}$ home care is not subsidized by the government or by insurance companies, making up 76.1\% of the total cost, while complementary treatments comprise $17.3 \%$ and transportation comprises $4.6 \%$. In Germany, ${ }^{33}$ caregiver costs are considered direct costs (there is no distinction between medical and nonmedical direct costs) and are partly subsidized by the state according to the patient's degree of disability: R $\$ 1,468.00$ (US\$405; first level), $\mathrm{R} \$ 3,521.00$ (US\$973; second level), and R\$5,464.00 (US\$1,513; third level) per month.

Certain governments such as those of Germany ${ }^{34}$ and other European countries ${ }^{6}$ subsidize part of the costs associated with walking sticks, wheelchairs, or walkers. Although in Brazil there are laws ${ }^{35}$ providing such forms of assistance to individuals with certain diseases or disabilities, these are not adequately enforced, which means that many patients end up privately paying for such resources. ${ }^{36}$

Naturally, the costs increase as the disease progresses. Studies ${ }^{37,38}$ have shown that the total mean cost for patients with an H\&Y score of 4 is almost twice that of patients with an $\mathrm{H} \& \mathrm{Y}$ score of 1 . In the $\mathrm{UK},{ }^{39}$ direct costs were most strongly correlated with disease-related disability, with score 5 being associated with a cost six times that of scores 0,1 , or 2. Similarly, in our study, scores 5 and 4 cost 4.8 and 2.9 times more than score 1, respectively. However, we did find that cost among H\&Y 3 patients was slightly lower than for H\&Y 2.5 patients. We believe this difference was probably related to a sample size bias (Table 3 ).

In summary, we observed that patients with PD presenting the highest costs are male and female patients 63 years of age or younger, who have had PD for more than 10 years, and have high H\&Y scores (ie, 5). Similarly, a study conducted in Spain in $2004^{40}$ revealed that younger patients with high $\mathrm{H} \& \mathrm{Y}$ scores, longer disease duration, and motor complications had the highest direct costs. By contrast, a study in Norway $^{41}$ suggested that higher costs are associated with older patients due to the higher incidence of dementia, which 
often results in institutionalization (in our study, these would be privately incurred caregiver costs).

Our study had methodological limitations that should be carefully addressed. First, since we tested patients at only two tertiary health centers in the metropolitan region of São Paulo, the results cannot be generalized to Brazil's entire population of PD patients. Our results do not consider the costs of treating patients in primary and secondary public services, which are likely to be lower. On the other hand, we also did not consider costs in a totally private health care environment or one which included surgical PD patients, which would be more expensive. Second, another limitation of this study was the exclusion of patient/caregiver incomes that could help understand the costs involved in having PD. Actually, at the time of our pilot study, we realized that requesting patient/ caregiver incomes would be an embarrassing question to these low-income background subjects, and this could impact our response rate, data reliability, and increase missing data. Third, we used a backdated 6-month period, which may have underestimated some costs. Fourth, we understand that an important drawback of our study was the so-called recall bias. As it is known, the impact of memory can account for $20 \%$ of critical details irretrievable after 1 year. ${ }^{42}$ Next, we understand that disease severity in PD is preferably evaluated during the "off"-state. However, patients in both hospitals were always requested to take their medication as usual and then were clinically evaluated in their "on"-state. Therefore, we understand that we could have found different costs regarding disease severity if we had evaluated patients in the "off"-state. Finally, the rate of non-returned questionnaires was $34 \%$, which is rather high. Nevertheless, we had a considerably large sample $(\mathrm{N}=260)$ and were able to correlate costs with in-person medical evaluations.

Another important consideration is that we did not correlate costs with possible motor fluctuations and dyskinesias, complications that generally require more drugs and greatly impact quality of life. We know that most patients with an H\&Y score of 3 or higher have a high prevalence of these complications.

As the first study of its kind conducted in Brazil, our work has begun to fill the knowledge gap regarding PD-associated costs in this country. We observed that PD exerts an overload on the public health system, on patients, and on the society in general. In our study sample, patients contributed $32.1 \%$ of the total annual cost of the disease (US\$1,873.2). Our results may provide public health managers with the necessary tools for better decision making, prioritization, and resource allocation to improve patients' quality of life. In addition, the current findings could help develop standardized ways of measuring PD-associated costs worldwide.

\section{Acknowledgments}

The authors thank all the patients, their relatives, and/or caregivers who participated in the study, as well as the responsible physicians and residents in the two outpatient clinics. They also thank the statistics, ethics, health economics, administrative, and library staff of the Hospital Israelita Albert Einstein for their invaluable support.

\section{Disclosure}

The authors report no conflicts of interest in this work.

\section{References}

1. Dorsey ER, Constantinescu R, Thompson JP, et al. Projected number of people with Parkinson disease in the most populous nations, 2005 through 2030. Neurology. 2006;68(5):384-386.

2. Andlin-Sobocki P, Jönsson B, Wittchen HU, Olesen J. Cost of disorders of the brain in Europe. Eur J Neurol. 2005;12(Suppl 1):1-27.

3. de Lau LML, Breteler MMB. Epidemiology of Parkinson's disease. Lancet Neurology. 2006;5(6):525-535.

4. Alves G, Forsaa EB, Pedersen KF, Gjerstad MD, Larsen JP. Epidemiology of Parkinson's disease. J Neurol. 2008;255(Suppl 5):18-32.

5. Bauso DJ, Tartari JP, Stefani CV, Rojas JI, Giunta DH, Cristiano E. Incidence and prevalence of Parkinson's disease in Buenos Aires City, Argentina. Eur J Neurol. 2012;19(8):1108-1113.

6. von Campenhausen S, Winter Y, Rodrigues e Silva A, et al. Costs of illness and care in Parkinson's Disease: an evaluation in six countries. Eur Neuropsychopharmacol. 2011;21(2):180-191.

7. Findley LJ. The economic impact of Parkinson's disease. Parkinsonism Relat Disord. 2007;13(Suppl):S8-S12.

8. McCrone P, Allcock LM, Burn DJ. Predicting the cost of Parkinson's disease. Mov Disord. 2007;22(6):804-812.

9. Zhao YJ, Tan LCS, Au WL, et al. Estimating the lifetime economic burden of Parkinson's disease in Singapore. Eur J Neurol. 2013;20(2): 368-374.

10. Bovolenta TM, de Azevedo Silva SM, Arb Saba R, Borges V, Ferraz HB, Felicio AC. Systematic review and critical analysis of cost studies associated with Parkinson's disease. Parkinson's Dis. 2017;2017: 3410946 .

11. Zhao YJ, Tan LCS, Li SC, et al. Economic burden of Parkinson's disease in Singapore. Eur J Neurol. 2011;18(3):519-526.

12. Johnson SJ, Kaltenboeck A, Diener M, et al. Costs of Parkinson's disease in a privately insured population. Pharmacoeconomics. 2013; 31(9):799-806.

13. Hoehn MM, Yahr MD. Parkinsonism: onset, progression, and mortality. 1967. Neurology. 1998;50(2):318 and 16 pages following.

14. Dowding CH, Shenton CL, Salek SS. A review of the health-related quality of life and economic impact of Parkinson's disease. Drugs Aging. 2006;23(9):693-721.

15. Boland DF, Stacy M. The economic and quality of life burden associated with Parkinson's disease: a focus on symptoms. Am J Manag Care. 2012;18(7 Suppl):S168-S175.

16. Duncan GW, Khoo TK, Yarnall AJ, et al. Health-related quality of life in early Parkinson's disease: the impact of nonmotor symptoms. Mov Disord. 2014;29(2):195-202.

17. Martinez-Martin P, Rodriguez-Blazquez C, Kurtis MM, Chaudhuri KR; Group NV. The impact of non-motor symptoms on health-related quality of life of patients with Parkinson's disease. Mov Disord. 2011; 26(3):399-406. 
18. Li H, Zhang M, Chen L, et al. Nonmotor symptoms are independently associated with impaired health-related quality of life in Chinese patients with Parkinson's disease. Mov Disord. 2010;25(16):2740-2746.

19. Reese JP, Dams J, Winter Y, Balzer-Geldsetzer M, Oertel WH, Dodel R. Pharmacoeconomic considerations of treating patients with advanced Parkinson's disease. Expert Opin Pharmacother. 2012; 13(7):939-958.

20. Gibb WR, Lees AJ. The relevance of the Lewy body to the pathogenesis of idiopathic Parkinson's disease. J Neurol Neurosurg Psychiatry. 1988;51(6):745-752.

21. Keranen T, Kaakkola S, Sotaniemi K, et al. Economic burden and quality of life impairment increase with severity of PD. Parkinsonism Relat Disord. 2003;9(3):163-168.

22. Tamás G, Gulácsi L, Bereczki D, et al. Quality of life and costs in Parkinson's disease: a cross sectional study in Hungary. PLoS One. 2014;9(9):e107704.

23. Altman DG. Practical Statistics for Medical Research. 1st ed. London: Chapman \& Hall/CRC; 1991.

24. IBM Corp ISSfW, Version 24.0, Armonk, NY: IBM Corp; 2016.

25. R Core Team. R: a language and environment for statistical computing. R Foundation for Statistical Computing V, Austria; 2015. Available from: http://www.R-project.org/. Accessed July 25, 2016.

26. Rodríguez-Blázquez C, Forjaz MJ, Lizán L, Paz S, Martínez-Martín P. Estimating the direct and indirect costs associated with Parkinsons disease. Expert Rev Pharmacoecon Outcomes Res. 2015;15(6):889-911.

27. Vargas AP, Carod-Artal FJ, Nunes SS, Melo M. Disability and use of healthcare resources in Brazilian patients with Parkinson's disease. Disabil Rehabil. 2008;30(14):1055-1062.

28. Winter Y, von Campenhausen S, Reese JP, et al. Costs of Parkinson's disease and antiparkinsonian pharmacotherapy: an Italian cohort study. Neurodegener Dis. 2010;7(6):365-372.

29. Vossius C, Gjerstad M, Baas H, Larsen JP. Drug costs for patients with Parkinson's disease in two different European countries. Acta Neurol Scand. 2006;113(4):228-232.

30. Cusso ME, Donald KJ, Khoo TK. The impact of physical activity on non-motor symptoms in Parkinson's disease: a systematic review. Front Med (Lausanne). 2016;3:35.

31. Redecker C, Bilsing A, Csoti I, et al. Physiotherapy in Parkinson's disease patients: Recommendations for clinical practice. Basal Ganglia. 2014;4(1):35-38.
32. Schrag A, Banks P. Time of loss of employment in Parkinson's disease. Mov Disord. 2006;21(11):1839-1843.

33. Winter Y, Balzer-Geldsetzer M, Spottke A, et al. Longitudinal study of the socioeconomic burden of Parkinson's disease in Germany. Eur J Neurol. 2010;17(9):1156-1163.

34. Spottke AE, Reuter M, Machat O, et al. Cost of illness and its predictors for Parkinson's disease in Germany. Pharmacoeconomics. 2005; 23(8):817-836.

35. Brazil. [Presidência da República. Lei ${ }^{\circ} 13.146$, de 06 de Julho de 2015. Institui a Lei Brasileira de Inclusão da Pessoa com Deficiência (Estatuto da Pessoa com Deficiência). Diário Oficial da República Federativa do Brasil, Brasília (DF)]. Avaiable from: http://www.planalto.gov.br/ccivil_03/_ato2015-2018/2015/lei/113146.htm. Accessed Jun 20, 2016.

36. Bovolenta TM, Felicio AC. How do demographic transitions and public health policies affect patients with Parkinson's disease in Brazil? Clin Interv Aging. 2017;12:197-205.

37. Wang G, Cheng Q, Zheng R, et al. Economic burden of Parkinson's disease in a developing country: a retrospective cost analysis in Shanghai, China. Mov Disord. 2006;21(9):1439-1443.

38. Hagell P, Nordling S, Reimer J, Grabowski M, Persson U. Resource use and costs in a Swedish cohort of patients with Parkinson's disease. Mov Disord. 2002;17(6):1213-1220.

39. Findley L, Aujla M, Bain PG, et al. Direct economic impact of Parkinson's disease: a research survey in the United Kingdom. Mov Disord. 2003;18(10):1139-1145.

40. Cubo E, Martínez Martin P, González M, Frades B; miembros del grupo ELEP. [Impact of motor and non-motor symptoms on the direct costs of Parkinson's disease]. Neurologia. 2009;24(1):15-23.

41. Vossius C, Larsen JP, Janvin C, Aarsland D. The economic impact of cognitive impairment in Parkinson's disease. Mov Disord. 2011;26(8): 1541-1544.

42. Bradburn NM, Rips LJ, Shevell SK. Answering autobiographical questions: the impact of memory and inference on surveys. Science. 1987;236(4798):157-161. 


\section{Supplementary material}

\section{Patient questionnaire}

\section{Welcome to my questionnaire}

The purpose of this questionnaire is to estimate the cost impact of Parkinson's disease on the healthcare system, as well as to determine other associated costs (ie, direct and indirect costs). All the information you provide here is classified and will only be used for the purpose of conducting the current research study. We request that you return the completed questionnaire within 15 days of receiving it.

\section{Your name}

1. What's your name?

2. You are participating in this research because you have Parkinson's disease. Right?
Yes
$\square$ No

\section{Direct medical costs}

3. This question is divided into 2 parts.

- In the "Number of pills per day" column, please indicate how many pills you take each day from the drugs listed below.

Example 1: If you take Levodopa $100 \mathrm{mg}+$ Benserazide $25 \mathrm{mg}$ and take a quarter (1/4) tablet 4 times a day, write down 1 (which corresponds to a whole $1 \mathrm{cp}$ per day).

Example 2: If you use Triexifenidil $5 \mathrm{mg}$ and take half a tablet once daily, write down 0.5 (which corresponds to $0.5 \mathrm{cp}$ per day).

- In the "Number of boxes" column, write the number of boxes you needed to buy of each drug listed below in the last 6 months, if you did not find them in the public network.

\begin{tabular}{|c|c|c|c|}
\hline Drugs & & Number of pills per day & Number of boxes \\
\hline Amantadine $100 \mathrm{mg}$ & 1 & & \\
\hline Biperiden & 2 & & \\
\hline Bromocriptine 2, $5 \mathrm{mg}$ & 3 & & \\
\hline Entacapone $200 \mathrm{mg}$ & 4 & & \\
\hline Levodopa 100 mg + Benserazide 25 mg (BD) & 5 & & \\
\hline Levodopa 100 mg + Benserazide 25 mg (HBS) & 6 & & \\
\hline Levodopa 100 mg + Benserazide 25 mg (dispersible) & 7 & & \\
\hline Levodopa $200 \mathrm{mg}$ + Benserazide $50 \mathrm{mg}$ & 8 & & \\
\hline Levodopa $200 \mathrm{mg}$ + Benserazide $50 \mathrm{mg}$ & 9 & & \\
\hline Levodopa $200 \mathrm{mg}+$ Carbidopa 50 mg & 10 & & \\
\hline Levodopa $250 \mathrm{mg}+$ Carbidopa $25 \mathrm{mg}$ & 11 & & \\
\hline Pramipexole $0.125 \mathrm{mg}$ & 12 & & \\
\hline Pramipexole $0.25 \mathrm{mg}$ & 13 & & \\
\hline Pramipexole I mg (Sifrol/Livipark/Pramipezan/Stabil) & 14 & & \\
\hline Pramipexole ER $0.375 \mathrm{mg}$ & 15 & & \\
\hline Pramipexole ER $0.75 \mathrm{mg}$ & 16 & & \\
\hline Pramipexole ER $1.5 \mathrm{mg}$ & 17 & & \\
\hline Pramipexole ER $3 \mathrm{mg}$ & 18 & & \\
\hline Rotigotine $2 \mathrm{mg} / 24 \mathrm{~h}$ & 19 & & \\
\hline Rotigotine $4 \mathrm{mg} / 24 \mathrm{~h}$ & 20 & & \\
\hline Rotigotine $6 \mathrm{mg} / 24 \mathrm{~h}$ & 21 & & \\
\hline Rotigotine $8 \mathrm{mg} / 24 \mathrm{~h}$ & 22 & & \\
\hline
\end{tabular}




\begin{tabular}{|l|l|l|l|}
\hline Drugs & & Number of pills per day & Number of boxes \\
\hline Rasagiline I mg & 23 & & \\
\hline Selegiline I0 mg (Niar/Jumexil) & 24 & & \\
\hline Selegiline $5 \mathrm{mg}$ (Niar/Jumexil) & 25 & & \\
\hline Stalevo 50 (Levodopa $50 \mathrm{mg}+$ Carbidopa $25 \mathrm{mg}+$ Entacapone $200 \mathrm{mg})$ & 26 & & \\
\hline Stalevo 100 (Levodopa $100 \mathrm{mg}+$ Carbidopa $25 \mathrm{mg}+$ Entacapone $200 \mathrm{mg})$ & 27 & & \\
\hline Stalevo 150 (Levodopa $150 \mathrm{mg}+$ Carbidopa $25 \mathrm{mg}+$ Entacapone $200 \mathrm{mg})$ & 28 & & \\
\hline Triexifenidil $2 \mathrm{mg}$ & 29 & & \\
\hline Triexifenidil $5 \mathrm{mg}$ & 30 & & \\
\hline
\end{tabular}

\section{This question is divided into 2 parts.}

- In the "Number of pills per day" column, please indicate how many pills you take each day from the drugs listed below.

Example 1: If you take Fluoxetine $20 \mathrm{mg}$ and take $2 \mathrm{cp}$ per day, note 2 (which corresponds to $2 \mathrm{cp}$ per day).

Example 2: If you take Memantine $10 \mathrm{mg}$ and take 1/2 tablet 2 times a day, write down 1 (which corresponds to a whole $1 \mathrm{cp}$ per day).

- In the "Number of boxes" column, write the number of boxes you needed to buy of each drug listed below in the last 6 months, if you did not find them in the public network.

\begin{tabular}{|c|c|c|c|}
\hline Drugs & & Number of pills per day & Number of boxes \\
\hline \multicolumn{4}{|l|}{ Group I } \\
\hline Fluoxetine $20 \mathrm{mg}$ & 31 & & \\
\hline Sertraline $25 \mathrm{mg}$ & 32 & & \\
\hline Sertraline $50 \mathrm{mg}$ & 33 & & \\
\hline Citalopran $20 \mathrm{mg}$ & 34 & & \\
\hline Escitalopran $5 \mathrm{mg}$ & 35 & & \\
\hline Paroxetina $20 \mathrm{mg}$ & 36 & & \\
\hline Amitriptilina $25 \mathrm{mg}$ & 37 & & \\
\hline Nortriptilina $10 \mathrm{mg}$ & 38 & & \\
\hline Nortriptilina 25 mg & 39 & & \\
\hline Trazodone $50 \mathrm{mg}$ & 40 & & \\
\hline Mirtazapine $30 \mathrm{mg}$ & $4 I$ & & \\
\hline Venlafaxine $37.5 \mathrm{mg}$ & 42 & & \\
\hline Venlafaxine $75 \mathrm{mg}$ & 43 & & \\
\hline Desvenlafaxine $50 \mathrm{mg}$ & 44 & & \\
\hline Desvenlafaxine $100 \mathrm{mg}$ & 45 & & \\
\hline Agomelatine $25 \mathrm{mg}$ & 46 & & \\
\hline \multicolumn{4}{|l|}{ Group 2} \\
\hline Rivastigmine $1.5 \mathrm{mg}$ & 47 & & \\
\hline Rivastigmine $3.0 \mathrm{mg}$ & 48 & & \\
\hline Rivastigmine $4.5 \mathrm{mg}$ & 49 & & \\
\hline Rivastigmine $6.0 \mathrm{mg}$ & 50 & & \\
\hline Donepezil hydrochloride $5 \mathrm{mg}$ & 51 & & \\
\hline Donepezil hydrochloride $10 \mathrm{mg}$ & 52 & & \\
\hline Galantamine $8 \mathrm{mg}$ & 53 & & \\
\hline Galantamine $16 \mathrm{mg}$ & 54 & & \\
\hline Galantamine $24 \mathrm{mg}$ & 55 & & \\
\hline Memantine $10 \mathrm{mg}$ & 56 & & \\
\hline
\end{tabular}




\begin{tabular}{|l|l|l|l|}
\hline Drugs & & Number of pills per day & Number of boxes \\
\hline Group 3 & & & \\
\hline Quetiapine $25 \mathrm{mg}$ & 57 & & \\
\hline Quetiapine $100 \mathrm{mg}$ & 58 & & \\
\hline Quetiapine $200 \mathrm{mg}$ & 59 & & \\
\hline Risperidone $1.0 \mathrm{mg}$ & 60 & & \\
\hline Risperidone $2.0 \mathrm{mg}$ & 61 & & \\
\hline Risperidone $3.0 \mathrm{mg}$ & 62 & & \\
\hline Clozapine $25 \mathrm{mg}$ & 63 & & \\
\hline Clozapine $100 \mathrm{mg}$ & 64 & & \\
\hline
\end{tabular}

5. How often do you go to the doctor exclusively because of Parkinson's disease? Write how many times you went to the doctor in the last 6 months and check in the corresponding space if the consultations were through the SUS/Servidor or another institution or association where you do not need to pay out of pocket (for example: Brazil Parkinson Association, AACD, Universities, etc.).

You may mark more than 1 alternative. Please indicate the cost of any private consultations and mark an "X" in the "I did not go" space if you did not go to any consultations in the last 6 months.

\begin{tabular}{|l|l|l|}
\hline Consultations & $\begin{array}{l}\text { How many times have you been to the consultations } \\
\text { in the last } \mathbf{6} \text { months because of Parkinson's disease? }\end{array}$ & $\begin{array}{l}\text { If you paid for the consultations, } \\
\text { check the amount of each }\end{array}$ \\
\hline SUS/Servidor & & - \\
\hline Another service without cost & & \\
\hline Private & & \\
\hline I did not go & & - \\
\hline
\end{tabular}

\section{Direct non-medical costs}

6. In the last 6 months, have you used any of the services listed below? In the appropriate space, indicate which therapies you used as well as how many times a week for each.

For example, if you used SUS/Servidor services, check the number of times per week in the SUS/Servidor column. If you used services at another institution or association where you are not required to pay (eg, Brazil Parkinson Association, AACD, universities, etc.), mark the number of times in the column "Other services without cost". Finally, if you had to pay for any of these therapies, mark the number of times in the private column and indicate the value of each session. If necessary, you may mark more than one alternative and more than one column.

Finally, if you did not use any therapy in the past 6 months, mark an "X" in the "I did not go" space.

\begin{tabular}{|l|l|l|l|l|}
\hline Therapy & $\begin{array}{l}\text { SUS/Servidor (number } \\
\text { of times per week) }\end{array}$ & $\begin{array}{l}\text { Other services without cost } \\
\text { (number of times per week) }\end{array}$ & $\begin{array}{l}\text { Private (number } \\
\text { of times per week) }\end{array}$ & $\begin{array}{l}\text { Value of each } \\
\text { particular session }\end{array}$ \\
\hline Physical therapy & & & & \\
\hline Speech therapy & & & & \\
\hline Occupation therapy & & & & \\
\hline Psychologist & & & & \\
\hline Nutritionist & & & & \\
\hline Physical educator & & & & \\
\hline Acupuncture & & & & \\
\hline Other & & & & \\
\hline I did not go & & & & \\
\hline
\end{tabular}




\section{Indirect costs}

7. In the last 6 months, have you received any kind of government assistance because of Parkinson's disease? Mark an "X" in the space labeled "I do not receive assistance" if the benefit you receive is equal to a retirement by length of service, or by age, or if you do not receive any type of assistance.

\begin{tabular}{|l|l|l|}
\hline Benefit & $\begin{array}{l}\text { If it is temporary, check for how } \\
\text { many months it has been granted }\end{array}$ & $\begin{array}{l}\text { Check the monthly amount of your } \\
\text { benefit (temporary or permanent) }\end{array}$ \\
\hline Permanent & - & \\
\hline Temporary & - & \\
\hline $\begin{array}{l}\text { I do not receive } \\
\text { assistance }\end{array}$ & - & - \\
\hline
\end{tabular}

\section{Out-of-pocket}

8. Indicate in the appropriate space whether or not you have a caregiver (ie, a person who takes care of you and helps you with daily tasks).

If you have a caregiver and do not pay for their services, mark an " $\mathrm{X}$ " in the "Yes" column of the specific type of caregiver.

If you have a caregiver and do pay for their services, indicate the amount of their monthly salary.

Finally, if you do not have a caregiver, mark an "X" in the space "I have no caregiver".

\begin{tabular}{|l|l|l|}
\hline Caregiver & Yes & Monthly value \\
\hline Relative (eg, wife, husband, children) & & \\
\hline Friend (eg, neighbor) & & \\
\hline Non-professional caregiver (eg, domestic worker) & & \\
\hline Professional caregiver (eg, nursing technician) & & \\
\hline Other (please specify) & & \\
\hline I have no caregiver & - & - \\
\hline
\end{tabular}

9. Only answer this question if you have a caregiver and do not pay for their services.

Has your caregiver stopped working to help you? If so, how long has he/she provided this service (in months) and what was his/her previous salary?

How long: $\quad$ Previous salary:

10. In the last 6 months, have you needed any changes/adaptations in your home due to Parkinson's disease? If not, mark an "X" in the "No" space and skip to question 13.

$\square$ Yes $\quad \square$ No

11. If you have made any changes/adaptations in your home, please explain what they were:

12. What is the approximate amount spent with changes/adaptations in your home, in the last 6 months? Only enter the value that corresponds to expenses related to these changes/adaptations.

13. In the last 6 months, have you needed any aids (walking stick, crutch, walker, wheelchair) to get around due to Parkinson's disease? If not, mark an "X" in the "No" space and skip to question 16.

$\square$ Yes $\square$ No 
14. If yes, please explain what resources you needed to get around due to Parkinson's disease:

15. What was the approximate amount you spent in the last 6 months with these walking aid(s)?

16. In the last 6 months, how much have you spent exclusively on Parkinson's disease-related needs (consider all expenses, including drugs, medical consultations, home adaptations, etc.)?

\section{Personal/demographic data}

17. Which of the following categories best describes your current employment status? If necessary, you may mark more than one alternative
$\square$ Unemployed
$\square$ Yes
$\square$ No
$\square$ Employed
$\square$ Yes
$\square$ No
$\square$ Retired
$\square$ Yes
$\square$ No
$\square$ Informal work
$\square$ Yes
$\square$ No

18. What is your gender?
$\square$ Male
Female

19. How old are you?

20. What is your level of education?
$\square$ I did not attend any school
Elementary school
High school
College
Graduate school
$\square$ Other (please specify)

21. How do you define your skin color?
$\square$ White
Brown
Black
Yellow

22. If you would like to inform us of any additional PD-related spending, please use the space below and give as much detail as possible regarding how the money was spent. Thank you for your cooperation. The information you provide is fundamental to our research.

Clinical Interventions in Aging

\section{Dovepress}

\section{Publish your work in this journal}

Clinical Interventions in Aging is an international, peer-reviewed journal focusing on evidence-based reports on the value or lack thereof of treatments intended to prevent or delay the onset of maladaptive correlates of aging in human beings. This journal is indexed on PubMed Central, MedLine,

CAS, Scopus and the Elsevier Bibliographic databases. The manuscript management system is completely online and includes a very quick and fair peer-review system, which is all easy to use. Visit http://www.dovepress. com/testimonials.php to read real quotes from published authors. 